\title{
Determinants of adverse pregnancy outcomes among Sickle Cell Disease deliveries at a tertiary hospital in Tanzania from 1999 to 2011
}

\author{
Projestine Muganyizi \\ Muhimbili University of Health and Allied Sciences (MUHAS), Dar es Salaam, Tanzania \\ Email:promuga@yahoo.com
}

Received 11 June 2013; revised 9 July 2013; accepted 16 July 2013

Copyright (C) 2013 Projestine Muganyizi. This is an open access article distributed under the Creative Commons Attribution License, which permits unrestricted use, distribution, and reproduction in any medium, provided the original work is properly cited.

\begin{abstract}
Purpose: Sub-Saharan Africa has the world's largest burden of Sickle Cell Disease (SCD), but due to poor care of SCD in childhood most do not reach reproductive ages. Consequently, due to sporadic cases of SCD in pregnancy, there has been little research attention to the problem in this sub region. This is one of the largest study series of SCD deliveries in Sub-Saharan Africa that aimed to establish the incidence and determinants of adverse pregnancy outcomes. Methods: Data of all deliveries from 1999 to 2011 at Muhimbili National Hospital (MNH) in Tanzania were analyzed. Deliveries of SCD were obtained and categorized according to presence or absence of adverse pregnancy outcomes based on set composite criteria. Using IBM SPSS statistics version 19, bivariate and multivariate logistic regression analyses were done to determine factors that were independently associated with adverse pregnancy outcomes. Statistics with p-value $<0.05$ were taken as significant. Results: There were 157,473 deliveries during the study period of which 149 were by SCD mothers. The incidence of adverse pregnancy outcomes was 624 per 1000 SCD deliveries. Compared to SCD without adverse outcomes, those with adverse outcomes were more likely to be referred from lower health facilities ( $37 \%$ versus $12.5 \%, P=0.001$ ), of lower mean gestation age ( $36.3 \pm 2.3$ versus $38.4 \pm 1.4, P<0.001)$, more prematurity rate $(50.7 \%$ versus $10.5 \%, \mathrm{P}<0.001)$, made lower mean number of antenatal visits $(4.7 \pm$ 2.2 versus $6.2 \pm 2.4, P<0.001)$ and delivered by cesarean section $(31.2 \%$ versus $19.6 \%, P<0.001)$. After adjusting for confounding factors, the odds of adverse outcomes were independently increased with referred compared to non-referred women $(\mathrm{OR}=4.4 ; 95 \% \mathrm{CI}$ : 1.2 - 16.8) and among Cesarean section deliveries
\end{abstract}

compared to vaginal deliveries $(\mathrm{OR}=4.2 ; 95 \% \mathrm{CI}$ : 1.2 - 14.6). The risk of adverse outcomes decreased as the gestation age increased $(\mathrm{OR}=0.4 ; 95 \% \mathrm{CI}: 0.3$ 0.6). Conclusion: The incidence of adverse pregnancy outcomes in SCD is unacceptably high mainly contributed by poor management and prematurity.

Keywords: Sickle Cell Disease; Pregnancy; Adverse Outcome; Tanzania

\section{INTRODUCTION}

Since about a hundred years ago when SCD was formerly reported, there has been very marked progress in terms of screening, diagnosis and care [1]. Africa, particularly sub-Saharan Africa is the most affected with more than two thirds of all the 300,000 annual SCD deliveries happening [1,2]. Despite of this burden, the management of SCD during childhood has lagged behind such that an estimated $50 \%-80 \%$ of SCD children in Sub-Saharan Africa die before cerebrating their fifth birthday. This situation is in sharp contrast to what is happening in countries with good standard of care where on average the life expectancy of SCD is at least the mid-50s $[3,4]$. Following this situation and the lack of reliable obstetrics registry databases for Sub-Saharan African countries, there has been scanty literature on $\mathrm{SCD}$ in pregnancy.

Internationally, SCD is associated with increased perinatal losses, maternal morbidity and mortality. The most commonly mentioned complications include spontaneous abortions, premature labor, fetal growth retardation, low birth weight, delivery by Caesarean section, infections, thromboembolic events, hypertensive disorders, hemorrhages and retained placenta [5-13]. Most studies seem to agree on increased adverse fetal outcomes but there is a wide discrepancy on the occurrence of maternal compli- 
cations among studies. An increased risk of pre-eclampsia and pregnancy-induced hypertension have been reported in some studies $[6,14]$ but denied by others $[5$, $10,11,15]$. Likewise increased risk for hemorrhage in SCD pregnancy and maternal mortality have been reported by some studies [5,7,16-18] but not all [6,10-11, $13,15]$. The above findings conclude that adverse perinatal and maternal outcomes are significant in SCD. The results also underscore the importance of understanding the local standards of care when interpreting the results. Impressive outcomes of SCD in pregnancy are not limited in high income countries. Some studies have reported impressive SCD delivery outcomes in low resource countries as a result of improved quality of care as the case of Benin and Jamaica $[7,18]$.

In more recent years, improved childhood illness management and survival have been reported in Sub-Saharan Africa. In Tanzania, infant deaths have decreased from 106 per 1000 five years ago to the current 81 per 1000 . This study utilizes data from electronic database in a tertiary hospital in Tanzania to determine the incidence and determinants of adverse pregnancy outcomes among SCD deliveries.

\section{METHODS}

This study focuses on the incidence of adverse outcomes occurring in SCD deliveries that took place in Muhimbili National Hospital (MNH) from January 1999 to December 2011. All the women and implicitly their babies were followed from admission due to a confirmed labor until maternal death or discharge. Data from antenatal cards, midwifery registers, admission books, case notes and maternal death audit reports were entered into electronic database for all deliveries. Electronic obstetric database at $\mathrm{MNH}$ was established in 1998 and has been continually entering obstetric data to-date. This database runs quality checks regularly by the internal and external (collaborating) experts. Using this database we analyzed the outcomes of all SCD deliveries during the study period.

Adverse outcomes were defined by the diagnosis of anyone of these; low APGAR at five minutes (Score less than 7), delivery of a stillbirth, delivery of a low birth weight baby (less than $2.5 \mathrm{Kg}$ ), presence of postpartum hemorrhage (blood loss $\geq 500 \mathrm{ml}$ ), and the occurrence of maternal death. The presence of any one of these five outcomes confirmed the diagnosis of adverse pregnancy outcomes. Independent variables included maternal age, referral status (whether came direct from home or referred from a health facility in labor), parity (including the just delivered fetus), gestational age, previous history of stillbirths, number of antenatal visits and mode of delivery (vaginal delivery or Cesarean section).

We performed bivariate logistic regression analyses to establish the association of individual independent variables with adverse pregnancy outcomes. Independent variables with a P-value equal to 0.5 or less on bivariate analyses were entered in a multivariate logistic regression model in order to determine variables that were independently associated with adverse pregnancy outcomes. In all statistics, p-values less than 0.05 were taken as significant. This study was ethically approved by the Research and Publications Committee at Muhimbili University of Health and Allied Sciences (MUHAS) and the permission to conduct the study was granted by $\mathrm{MNH}$ authorities.

\section{RESULTS}

A total of 157,473 deliveries were conducted during the study period of which 149 were by SCD. Out of these 149 SCD deliveries, adverse outcomes occurred in 93 which makes an incidence of 624 adverse pregnancy outcomes per 1000 SCD deliveries. Low birth weight and birth asphyxia were the most frequent adverse outcomes that occurred in $33.6 \%$ and $34.2 \%$ respectively (Table 1).

Table 1. Rates of adverse pregnancy outcomes among SCD deliveries at MNH, 1999-2011.

\begin{tabular}{|c|c|c|}
\hline Adverse outcome & Number & Percentag \\
\hline \multicolumn{3}{|c|}{ APGAR score at 5 minutes } \\
\hline$<7$ & 51 & 34.2 \\
\hline $7-10$ & 97 & 65.1 \\
\hline Missing & 1 & 0.7 \\
\hline \multicolumn{3}{|l|}{ Stilbirths } \\
\hline Yes & 38 & 25.5 \\
\hline No & 110 & 73.8 \\
\hline Missing & 1 & 0.7 \\
\hline \multicolumn{3}{|l|}{ Birth weight (Kg) } \\
\hline$<2.5$ & 50 & 33.6 \\
\hline 2.5 or above & 96 & 64.4 \\
\hline Missing & 3 & 2.0 \\
\hline \multicolumn{3}{|l|}{ Maternal outcome } \\
\hline Alive & 132 & 88.6 \\
\hline Died & 17 & 11.4 \\
\hline \multicolumn{3}{|c|}{ Postpartum Hemorrhage } \\
\hline Yes & 28 & 18.8 \\
\hline No & 120 & 80.5 \\
\hline Missing & 1 & 0.7 \\
\hline \multicolumn{3}{|l|}{ Any adverse outcome } \\
\hline Yes & 93 & 62.4 \\
\hline No & 56 & 37.6 \\
\hline
\end{tabular}


SCD deliveries that were complicated with adverse pregnancy outcomes had significantly more referred women $(37 \%)$ than those SCD deliveries without adverse events $(12.5 \%), p=0.001$. Likewise SCD deliveries with adverse pregnancy outcomes had lower mean gestation age and number of antenatal visits but higher prematurity and cesarean section rates (Table 2).

Six independent variables qualified and were entered in multivariate regression model (Table 3). Three variables emerged to be independently associated with adverse pregnancy outcomes among SCD deliveries. These variables include the status of referral, gestation age at delivery and mode of delivery. The risk of developing adverse pregnancy outcomes was more than four times when the woman was admitted from a referring hospital compared to when she arrived from home. The risk of adverse pregnancy outcomes was more than halved (60\%) as the gestation age increased by one week.

\section{DISCUSSION}

SCD in pregnancy is an emerging public health problem that calls for more attention in Sub-Saharan Africa. Todate this problem has not stimulated adequate attention from researchers in Sub-Saharan Africa due to an estimated low burden of SCD in pregnancy and the lack of sound databases to capture sporadic cases that occur over a prolonged period of time. This is one of the largest series of SCD deliveries in Sub-Saharan Africa able to compare SCD deliveries with and without adverse outcomes. The current study has showed that the incidence of adverse pregnancy outcomes was high among SCD deliveries with more than two thirds of all SCD deliveries ending in one or more adverse outcomes. This high incidence of adverse outcomes concurs with the findings by other international studies that generally report increased adverse pregnancy outcomes among SCD

Table 2. Stratified analysis of independent variables according to presence or absence of adverse pregnancy outcomes.

\begin{tabular}{|c|c|c|c|}
\hline \multirow{2}{*}{ Variable } & \multicolumn{2}{|c|}{ Presence of adverse outcome } & \multirow{2}{*}{ p-value } \\
\hline & No & Yes & \\
\hline Mean maternal age (mean \pm SD) Age at delivery (years) & $24.3 \pm 5.4$ & $23.8 \pm 5.6$ & 0.5 \\
\hline$<18$ & $5(8.9)$ & $10(10.8)$ & \\
\hline $18+$ & $51(91.1)$ & $83(89.2)$ & 0.7 \\
\hline \multicolumn{4}{|l|}{ Status of referral } \\
\hline Not referred & $49(87.5)$ & $58(63.0)$ & \\
\hline Referred & $7(12.5)$ & $34(37.0)$ & 0.001 \\
\hline Parity (Mean \pm SD) & $1.6 \pm 0.9$ & $1.7 \pm 1.0$ & 0.7 \\
\hline \multicolumn{4}{|l|}{ Parity level } \\
\hline $0-4$ & $55(98.2)$ & $91(97.8)$ & \\
\hline 5 or more & $1(1.8)$ & $2(2.2)$ & 0.9 \\
\hline Gestation Age (mean \pm SD) & $38.4 \pm 1.4$ & $36.3 \pm 2.3$ & $<0.001$ \\
\hline \multicolumn{4}{|l|}{ Premature delivery } \\
\hline No & $34(89.5)$ & $36(49.3)$ & $<0.001$ \\
\hline Yes & $4(10.5)$ & $37(50.7)$ & \\
\hline \multicolumn{4}{|l|}{ Previous stillbirths } \\
\hline No & $46(82.1)$ & $85(92.4)$ & \\
\hline Yes & $10(17.9)$ & $7(7.6)$ & 0.07 \\
\hline No. of antenatal visits (Mean \pm SD) & $6.2 \pm 2.4$ & $4.7 \pm 2.2$ & $<0.001$ \\
\hline \multicolumn{4}{|l|}{ Antenatal visit levels } \\
\hline $5+$ & $41(73.2)$ & $46(49.5)$ & \\
\hline $1-4$ & $15(26.8)$ & $47(50.5)$ & 0.002 \\
\hline \multicolumn{4}{|l|}{ Mode of delivery } \\
\hline Vaginal & $45(80.4)$ & $64(68.8)$ & \\
\hline Cesarean section & $11(19.6)$ & $29(31.2)$ & $<0.001$ \\
\hline
\end{tabular}


Table 3. Bivariate and multivariate logistic regression analyses for determination of adverse pregnancy outcomes among SCD deliveries at $\mathrm{MNH}$.

\begin{tabular}{|c|c|c|c|}
\hline \multirow{2}{*}{ Characteristics } & \multicolumn{2}{|c|}{ OR $(95 \% \mathrm{CI})$} & \multirow{2}{*}{ P-value } \\
\hline & Unadjusted & Adjusted & \\
\hline Maternal age (years) & $1.0(0.9-1.0)$ & $1.0(0.9-1.1)$ & 0.7 \\
\hline \multicolumn{4}{|l|}{ Status of referral } \\
\hline Not referred & 1 & 1 & \\
\hline Referred & $4.1(1.7-10.1)$ & $4.4(1.2-16.8)$ & 0.03 \\
\hline Gestation Age (weeks) & $0.5(0.3-0.6)$ & $0.4(0.3-0.6)$ & $<0.001$ \\
\hline \multicolumn{4}{|l|}{ Previous stillbirths } \\
\hline Yes & 1 & 1 & \\
\hline No & $0.4(0.1-1.1)$ & $0.7(0.2-3.0)$ & 0.6 \\
\hline Number of Antenatal visits & $0.8(0.7-0.9)$ & $0.8(0.7-1.0)$ & 0.1 \\
\hline \multicolumn{4}{|l|}{ Mode of delivery } \\
\hline Vaginal & 1 & 1 & \\
\hline Cesarean section & $1.9(0.8-4.1)$ & $4.2(1.2-14.6)$ & 0.02 \\
\hline
\end{tabular}

deliveries [5-11,13,17-19].

In the current study low number of antenatal visits, low gestation age, delivery by cesarean section and admission through a lower level hospital were all associated with adverse outcomes. These variables may be seen as proxy indicators of prenatal care (antenatal visits, mode of delivery and referral) or prenatal fetal condition (gestation age/prematurity). Studies have shown that women with SCD in pregnancy seek prenatal care services more frequently than the non SCD [5,7] but to what extent these services help them largely depends on the quality of offered services. In Benin, for example, the observed excessive adverse pregnancy outcomes among SCD deliveries were very markedly alleviated with the introduction of a better standard of care [18]. In the current study the importance of antenatal visits made by SCD mothers in reducing adverse outcomes was seen on a bivariate logistic regression but was lost after adjusting for confounders suggesting that the mere frequency of antenatal visits is insufficient to improve SCD pregnancy outcomes if a more comprehensive standard care is not implemented. Thus, meticulous antenatal care is needed if antenatal visits are to be consistently effective in preventing adverse delivery outcomes [6].

The referral status of SCD women was associated with adverse pregnancy outcomes. Women admitted in labor at a tertiary hospital after care in lower health facilities were more than four times likely to end up with adverse pregnancy outcomes as compared with those admitted directly from home. Unlike antenatal visits, the risk associated with referral status persisted independent of other factors. The likely explanation for this could be a bias towards referral of more severely sick women from lower level health facilities as is the experience in other tertiary hospitals in Africa [18]. In countries where care of SCD in pregnancy is standard, delivery is conducted in centers where comprehensive services for the mother and newborn can be readily available in order to minimize complications. A four-fold risk associated with Cesarean delivery as compared to vaginal delivery was also noted independent of other factors. Studies elsewhere report increased Cesarean delivery among SCD [8,20-21] and the disease is not considered a contraindication for this mode of delivery. The increased risk for adverse pregnancy outcomes in the current study could be explained by the limited attention paid to anaesthetic selection with a preference of general anesthesia rather than regional analgesia in the study setting. SCD patients have increased risk of end organ damage thus being poor candidates for general anaesthesia and Pethidine which is linked with seizures [22]. Likewise, in the absence of a guiding protocol, it is unlikely that perioperative management in SCD can be of the standard expected to reduce the consequences of surgery [9]. At MNH the use of regional analgesia for Cesarean section has evolved in the past decade from very low use of regional analgesia for Cesarean section in early 1990s to the current situation where only a few exceptions receive general anaesthesia. Unfortunately, data on other factors that are related to surgery and could impact negatively on SCD outcomes such as poor perioperative management and sepsis were not available to control for. All these inefficiencies could have contributed to poor delivery outcomes of mothers delivered by Cesarean section at 
MNH.

An increase in gestation age was associated with a reduction in the risk of adverse pregnancy outcomes. Our findings also suggest that prematurity was associated with increased risk for adverse events. Both these findings could be anticipated since our composite adverse pregnancy outcomes variable included low birth weight component. Low birth weight is the most consistent finding in studies that have addressed fetal outcomes in SCD $[4-10,12,13,16,21,23]$. Its persistence even in settings where SCD management in pregnancy has been standard shows how difficult it is to prevent.

This study has several limitations. The use of recorded data denied the flexibility to use all the desired information such as socio-demographic, intrapartum and postpartum care data to enable us to control for most of the desirable variables. Some variables had incomplete data necessitating dropping some of them. The diagnosis of SCD was based on the prior diagnosis usually made in childhood; hence it was not possible to sub-group the patients into their genotypic categories of SCD which would have been more informative. Nevertheless, the 149 SCD deliveries in the current study is one of the largest series of SCD in this sub region and has provided insights on the adverse pregnancy outcomes associated with the problem. Future prospective studies should be able to solve the limitations encountered in this study.

\section{ACKNOWLEDGEMENTS}

I wish to acknowledge the assistance from Dr. H.Kidanto in his capacity as the in-charge of the obstetric database at $\mathrm{MNH}$.

\section{REFERENCES}

[1] Serjeant, G.R. (2010) One hundred years of sickle cell disease. British Journal of Haematology, 151, 425-429. doi:10.1111/j.1365-2141.2010.08419.x

[2] Diallo, D. and Tchernia, G. (2002) Sickle cell disease in Africa. Current Opinion in Hematology, 9, 111-116. doi:10.1097/00062752-200203000-00005

[3] Wierenga, K.J., Hambleton, I.R. and Lewis, N.A. (2001) Survival estimates for patients with homozygous sicklecell disease in Jamaica: A clinic-based population study. Lancet, 357, 680-683. doi:10.1016/S0140-6736(00)04132-5

[4] Quinn, C.T., Rogers, Z.R. and Buchanan, G.R. (2004) Survival of children with sickle cell disease. Blood, 103, 4023-4027. doi:10.1182/blood-2003-11-3758

[5] Afolabi, B.B., et al. (2009) Morbidity and mortality in sickle cell pregnancies in Lagos, Nigeria: A case control study. Journal of Obstetrics \& Gynaecology, 29, 104-106. doi:10.1080/01443610802667112

[6] Al Jama, F.E., et al. (2009) Pregnancy outcome in patients with homozygous sickle cell disease in a university hospital, Eastern Saudi Arabia. Archives of Gynecology and Obstetrics, 280, 793-797.

doi:10.1007/s00404-009-1002-7

[7] Asnani, M.R., McCaw-Binns, A.M. and Reid, M.E. (2011) Excess risk of maternal death from sickle cell disease in Jamaica: 1998-2007. PLoS ONE, 6, e26281.

doi:10.1371/journal.pone.0026281

[8] Barfield, W.D., et al. (2010) Sickle cell disease and pregnancy outcomes: Women of African descent. American Journal of Preventive Medicine, 38, S542-S549. doi:10.1016/j.amepre.2009.12.020

[9] Rajab, K.E. and Skerman, J.H. (2004) Sickle cell disease in pregnancy. Obstetric and anesthetic management perspectives. SAUDI Medical Journal, 25, 265-276.

[10] Serjeant, G.R. (2005) Mortality from sickle cell disease in Africa. British Medical Journal, 330, 432-433. doi:10.1136/bmj.330.7489.432

[11] Serjeant, G.R., et al. (2004) Outcome of pregnancy in homozygous sickle cell disease. Obstetrics \& Gynecology, 103, 1278-1285. doi:10.1097/01.AOG.0000127433.23611.54

[12] Smith, J.A., et al. (1996) Pregnancy in sickle cell disease: Experience of the cooperative study of sickle cell disease. Obstetrics \& Gynecology, 87, 199-204. doi:10.1016/0029-7844(95)00367-3

[13] Sun, P.M., et al. (2001) Sickle cell disease in pregnancy: Twenty years of experience at Grady Memorial Hospital, Atlanta. American Journal of Obstetrics \& Gynecology, 184, 1127-1130. doi:10.1067/mob.2001.115477

[14] Chakravarty, E.F., Khanna, D. and Chung, L. (2008) Pregnancy outcomes in systemic sclerosis, primary pulmonary hypertension, and sickle cell disease. Obstetrics \& Gynecology, 111, 927-934. doi:10.1097/01.AOG.0000308710.86880.a6

[15] Serjeant, G.R., Hambleton, I. and Thame, M. (2005) Fecundity and pregnancy outcome in a cohort with sickle cell-haemoglobin C disease followed from birth. BJOG: An International Journal of Obstetrics \& Gynaecology, 112, 1308-14. doi:10.1111/j.1471-0528.2005.00678.x

[16] Ogedengbe, O.K. and Akinyanju, O. (1993) The pattern of sickle cell disease in pregnancy in Lagos, Nigeria. West African Journal of Medicine, 12, 96-100.

[17] Dare, F.O., Makinde, O.O. and Faasuba, O.B. (1992) The obstetrics performance of sickle cell disease patients and homozygous $\mathrm{C}$ disease patients in Ile-Ife, Nigeria. International Journal of Gynecology \& Obstetrics, 37, 163. doi:10.1016/0020-7292(92)90376-T

[18] Rahimy, M.C., et al. (2000) Effect of active prenatal management on pregnancy outcome in sickle cell disease in an African setting. Blood, 96, 1685-1689.

[19] el-Shafei, A.M., Sandhu, A.K. and Dhaliwal, J.K. (1988) Maternal mortality in Bahrain with special reference to sickle cell disease. Australian and New Zealand Journal of Obstetrics and Gynaecology, 28, 41-44. doi:10.1111/j.1479-828X.1988.tb01609.x

[20] Simms-Stewart, D., et al. (2009) Retained placenta in homozygous sickle cell disease. Obstetrics \& Gynecology, 114, 825-828. doi:10.1097/AOG.0b013e3181b6f762 
[21] Villers, M.S., et al. (2008) Morbidity associated with sickle cell disease in pregnancy. American Journal of $\mathrm{Ob}$ stetrics \& Gynecology, 199, 125.

[22] Rees, D.C., et al. (2003) Guidelines for the management of the acute painful crisis in sickle cell disease. British
Journal of Haematology, 120, 744-752. doi:10.1046/j.1365-2141.2003.04193.x

[23] Stuart, M.J. and Nagel, R.L. (2004) Sickle-cell disease. Lancet, 364, 1343-1360. 